\title{
Novel Synthesis and Characterization of 2-Aminobenzimidazole Derivative
}

\author{
R Sriram ${ }^{1}$, R Sapthagiri ${ }^{1}$, A Ravi $^{2 *}$ \\ ${ }^{1}$ Research Scholars, PG \& Research Department of Chemistry, Government Arts College, Tiruvannamalai-606603, Tamil Nadu, India \\ ${ }^{2}$ Assistant professor, PG \& Research Department of Chemistry, Government Arts College, Tiruvannamalai-606603, Tamil Nadu, India
}

Received: June 30, 2015; Accepted: July 14, 2015; Published: July 30, 2015

*Corresponding author: A Ravi, Assistant professor, PG \& Research Department of Chemistry, Government Arts College, Tiruvannamalai-606603, Tamil Nadu, India, E-mail: draravitvm@gmail.com

\begin{abstract}
An efficient method for the synthesis of 2-aminobenzimidazole derivative using iodoacetic acid mediated cyclization of thiourea. This method is also applicable to the synthesis of more challenging derivative such as 7-(methanesulphonaminomethyl)-N-(1-(3(trifluoromethyl) phenyl) ethyl)-1H-benzo[d]imidazol-2-amine. The method was simpler and giving high yield of the target molecule.

Keywords:3-methylbenzene-1,2-diamine;1-(3-(trifluoromethyl) phenyl)ethanamine; NBS; Raney nickel; Methanesulphonylchloride; Iodoacetic acid; N-((2-(1-(3-(trifluoromethyl)phenyl)ethylamino)1 H-benzo[d]imidazol-4-yl) methyl) methanesulfonamide
\end{abstract}

\section{Introduction}

Generally benzimidazole derivatives in numerous categories of therapeutic agent such as antimicrobial, antiviral, anti inflammatory, antioxidant, anticancer, anticoagulant, liquid level modulator, antidiabetics etc., various substituted around the benzimidazole nucleus have provided a wide biological activities. Important of this nucleus we are synthesized novel 2-aminobenzimidazole such as like $\mathrm{N}$-((2-(1-(3-(trifluoromethyl) phenyl) ethylamino)-1H-benzo[d]imidazol-4-yl) methyl) methanesulfonamide. Aminobenzimidazoles are interesting heterocycles that are found in natural products as well as drugs and number of biologically active molecules [1]. The synthesis of 2-aminobenzimidazole involves the cyclodesulfurization of a pre-formed thiourea. The reported desulfurization agents was mercury(II) oxide [2], mercury(II) chloride [3], copper(I) chloride [4], methyl iodide [5], tosyl chloride [6], dicyclohexyl carbodiimide [7], PhI(OAc)2 [8] and polymer supported carbodiimide [9] etc., the reported method was frequently required heating and long reaction time. Furthermore formation of urea side product can pose significant challenges during purification. The variety of 2 -aminobenzimidazole derivatives synthesized from diverse isothiocyanates (electron donating and electron withdrawing) groups was well tolerating the reaction.

We recognized that this process could be considerably simplified by using iodoaceic acid as a cyclodesulfurization agent and using ethanol solvent to provide desired product at $60^{\circ} \mathrm{C}, 3$ hours without formation of side product with high yield.

\section{Experimental}

\section{Methods and materials}

The chemicals of 3-methylbenzene-1,2-diamine, 1-(3-(trifluoromethyl)phenyl) ethanamine, NBS, methanesulphonylchloride, iodoacetic acid, thionyl chloride were obtained from Avra chemicals and Raney nickel was purchased from Aldrich. Silica gel (TLC and Column grade) were purchased from Merck.

FTIR spectra (KBr pellets) were measured using Alpha Bruker FTIR instrument scanning with the entire region of $4000-400$ $\mathrm{cm}^{-1}$ with typical resolution of $1.0 \mathrm{~cm}^{-1}$. The NMR spectra of the compounds have been recorded on Bruker AV400 spectrometer operating at $400 \mathrm{MHz}$ for recording ${ }^{1} \mathrm{H} \mathrm{NMR}$ spectra in $\mathrm{CDCl}_{3}$ as solvent using TMS as internal standard. Mass spectra have been recorded on SHIMADZU spectrometer using chemical ionization technique.

\section{Synthesis}

Preparation of 7-(methanesulphonaminomethyl)-N-(1(3-(trifluoromethyl)phenyl)ethyl)-1H-benzo[d]imidazol2-amine: To a solution of N-(2,3-diaminobenzyl)methanesulfonamide (1) (3g, 0.0139mmol, 1eq), 1-(trifluoromethyl)-3-(1isothiocyanatoethyl)benzene (2) $(3.2 \mathrm{~g}, 0.0139 \mathrm{mmol}, 1 \mathrm{eq})$ and iodoacetic acid $(1.7 \mathrm{~g}, 0.0139 \mathrm{mmol}, 1 \mathrm{eq})$ in $30 \mathrm{~mL}$ of anhydrous ethanol was added at $0^{\circ} \mathrm{C}$. The reaction mixture was heated at $60^{\circ} \mathrm{C}$ and stirred for $3 \mathrm{hrs}$. TLC was indicated absence of N-(2,3diaminobenzyl)methanesulfonamide. The residue was diluted with water and then extracted with Dichloro methane $\left(30 \mathrm{ml}^{*}\right.$ 3times). The combined organic layer washed with brine solution and dried with anhydrous sodium sulphate and filtered, concentrated in vacuum to afford crude product. The crude was purified by (60-120mesh silica gel) chromatography column using chloroform, ethanol as eluvent $(90: 10)$ to get pure desired product as ethyl 7-(methanesulphonaminomethyl)-N-(1-(3(trifluoromethyl)phenyl)ethyl)-1H-benzo[d]imidazol-2-amine (3) $(3.5 \mathrm{~g}$,) with $92 \%$ yield. 


\section{Results and Discussion}

Spectral details of 7-(methanesulphonaminomethyl)-N(1-(3-(trifluoromethyl) phenyl)ethyl)-1H-benzo[d]imidazol-2-amine IR (film): $3332(\mathrm{NH}), 3365(\mathrm{NH})$ and Aromatic C-H (2966) $\mathrm{cm}^{-1}$ Mass (m/z): Calculated M.W: 413.0, Observed M.W: $414.0(\mathrm{M}+1$ (Figure 1)

${ }^{1}$ H NMR (300 MHz, DMSO -d6): $\boldsymbol{\delta}=10.94$ (s, 1H -NH), 7.81 (s, $1 \mathrm{H}-\mathrm{NH}), 7.74(\mathrm{~s}, 1 \mathrm{H},-\mathrm{NH}) 7.57(\mathrm{~s}, 1 \mathrm{H}, \mathrm{Ar}-\mathrm{H}), 7.53(\mathrm{~d}, 1 \mathrm{H}, \mathrm{J}=9$ $\mathrm{Hz}, \mathrm{Ar}-\mathrm{H}), 7.315-7.575(\mathrm{~m}, 2 \mathrm{H}, \mathrm{Ar}-\mathrm{H}), 7.03(\mathrm{~d}, 1 \mathrm{H}, \mathrm{J}=7.5 \mathrm{~Hz}, \mathrm{Ar}-$ $\mathrm{H}), 6.92(\mathrm{~d}, 1 \mathrm{H}, \mathrm{J}=6.9 \mathrm{~Hz}, \mathrm{Ar}-\mathrm{H}), 6.84-6.83(\mathrm{~d}, 1 \mathrm{H}, \mathrm{J}=5.7 \mathrm{~Hz}, \mathrm{Ar}-\mathrm{H})$, $5.06(\mathrm{~m}, 1 \mathrm{H}$, Ali- $\mathrm{CH}), 4.33$ (broad s, $\left.2 \mathrm{H},-\mathrm{CH}_{2}\right), 2.75\left(\mathrm{~s}, 3 \mathrm{H},-\mathrm{CH}_{3}\right)$, $1.50\left(\mathrm{~d}, 3 \mathrm{H}, \mathrm{J}=6.9 \mathrm{~Hz},-\mathrm{CH}_{3}\right)$ (Figure 2).

${ }^{13}$ C NMR (100.6MHz, DMSO d-6): $\boldsymbol{\delta}=169.0,155.1$, $147.7,130.7,129.7,129.5,129.2,126.1,123.8,122.8,120.3$, 113.6, 106.3, 72.0, 59.0, 51.7, 42.5, 23.9 (Figure 3) Figure (1-3) revealed the Mass, ${ }^{1} \mathrm{H}$ NMR and ${ }^{13} \mathrm{C}$ NMR spectra of 7-(methanesulphonaminomethyl)-N-(1-(3-(trifluoromethyl) phenyl)ethyl)-1H-benzo[d]imidazol-2-amine (3) respectively using compound 1 and 2 with ethanol as solvent in the presence of iodoacetic acid has been shown in the scheme 1 .

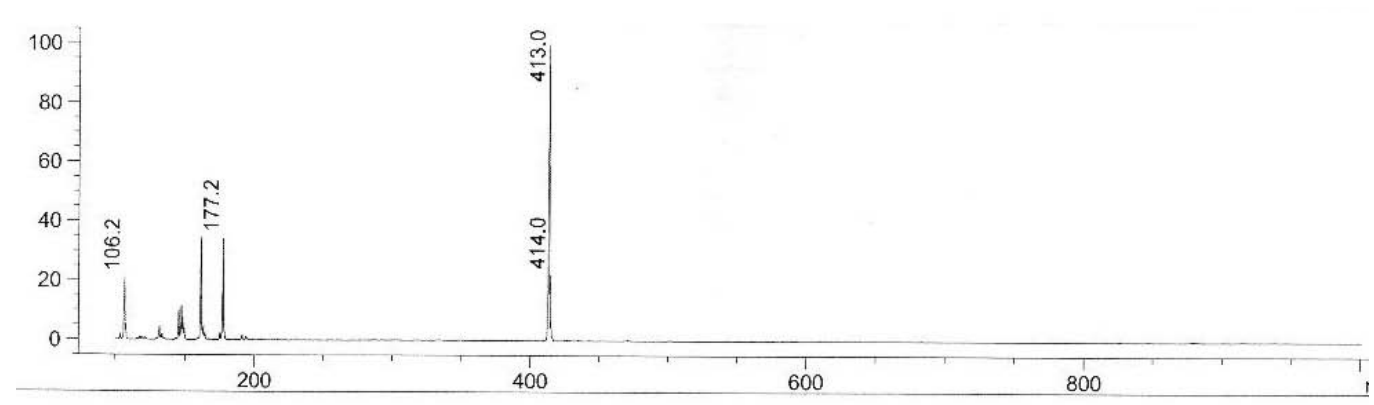

Figure 1: MASS Spectrum of the Compound.
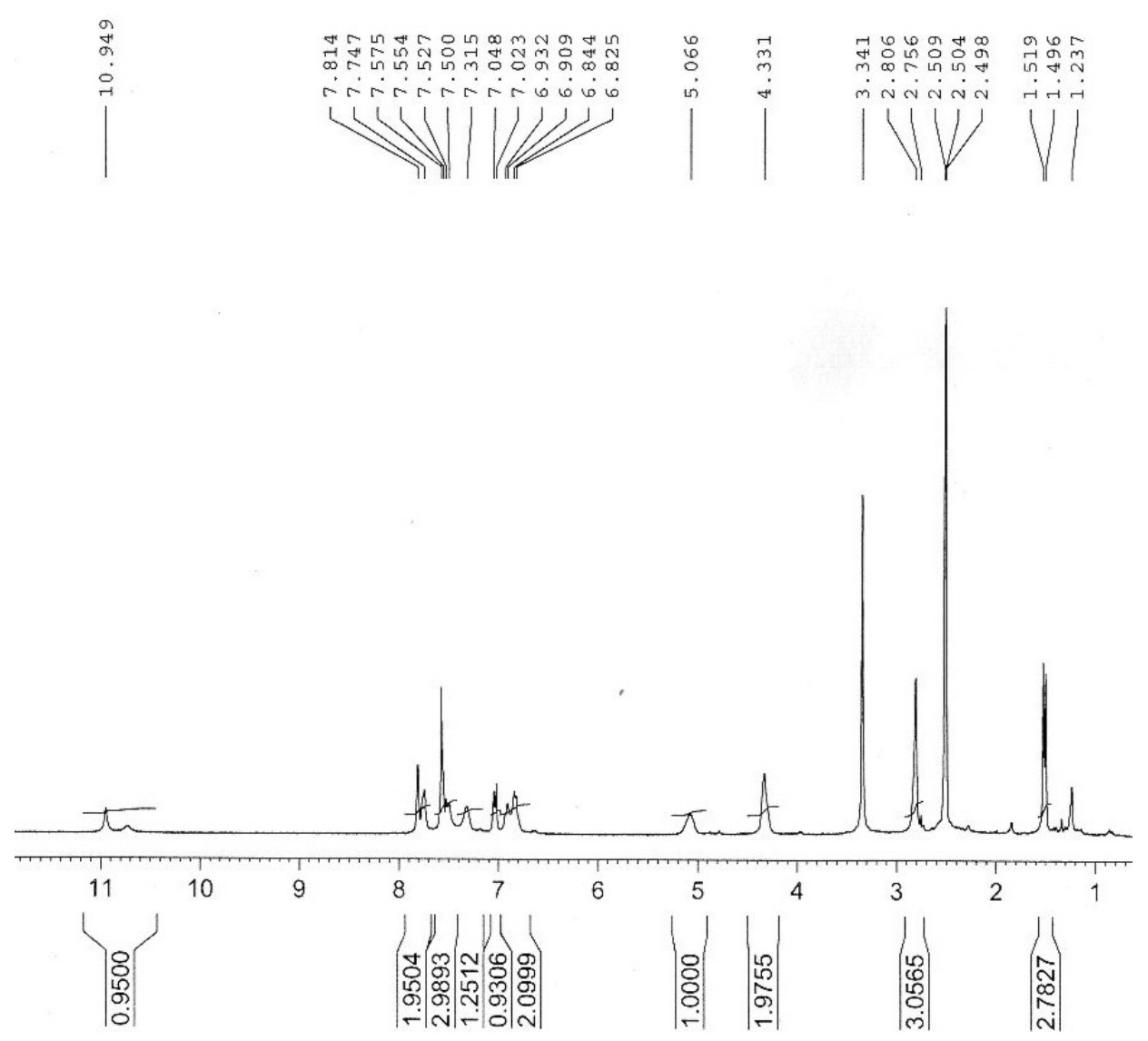

Figure 2: ${ }^{1} \mathrm{H}$ NMR Spectrum of the Compound. 


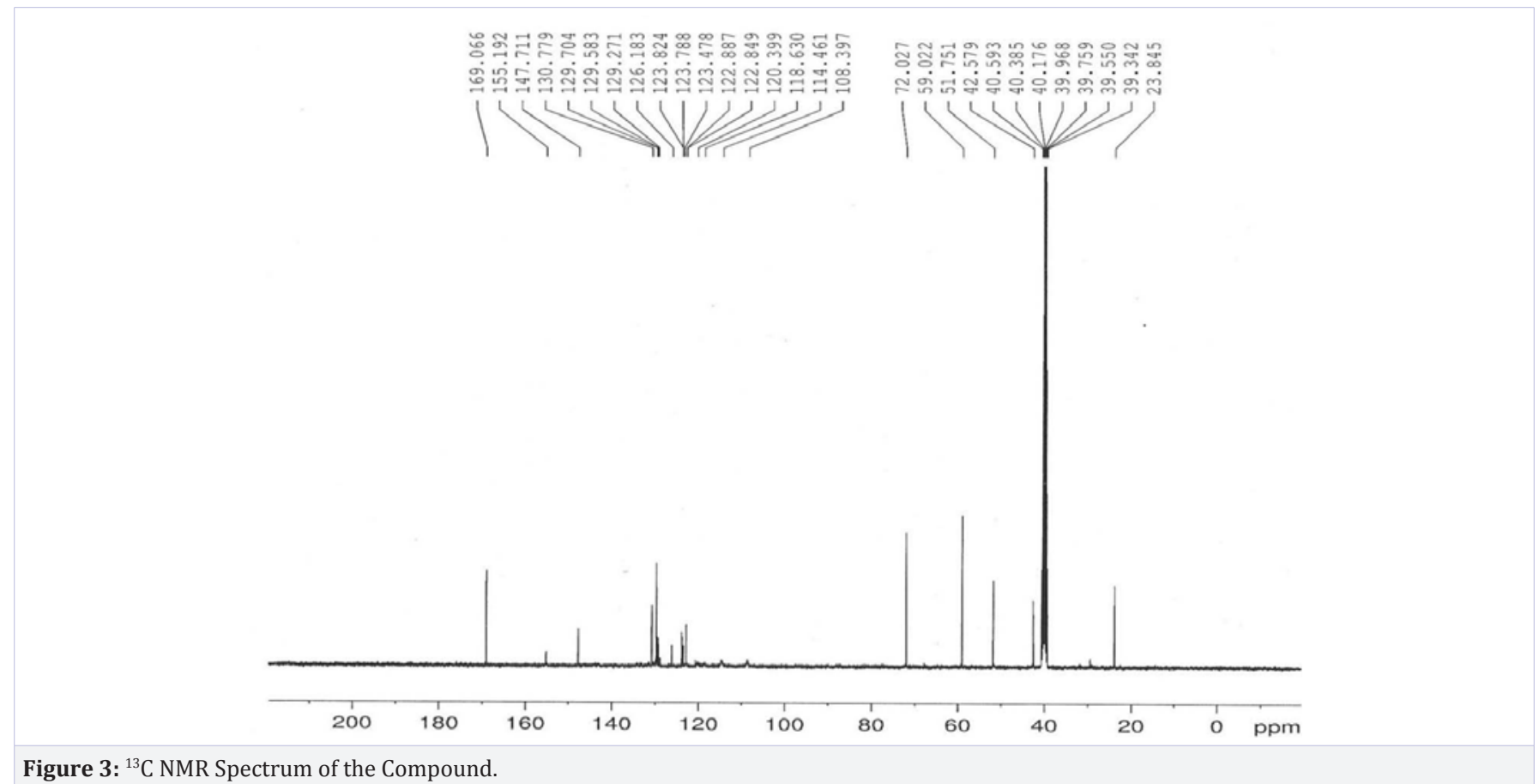

Figure $3:{ }^{13} \mathrm{C}$ NMR Spectrum of the Compound.

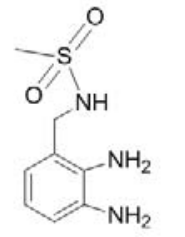

(1)<smiles></smiles>

(2)

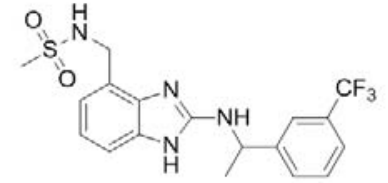

(3)
FTIR spectra of compound 3 have been provided a preliminary idea for the formation of product. According to the FTIR, the presence of peak at $3480 \mathrm{~cm}^{-1}$ has clearly noticed the utilization of starting materials transforms into the product. Further, the corresponding peaks at 3332, 3365 and $2966 \mathrm{~cm}^{-1}$ have been related to aliphatic $\mathrm{N}-\mathrm{H}$, benzimidazole ring $\mathrm{N}-\mathrm{H}, \mathrm{C}-\mathrm{H}$ aromatic stretching in the compound 3. The concerned mass of the compound 3 is in good agreement with the observed $(414.0 \mathrm{~m} / \mathrm{z})$ and calculated value $(413.0 \mathrm{~m} / \mathrm{z})$ were shown in Figure 1 Proton NMR strongly empowered for the formation of the product by its $\delta$ value. In proton NMR the three exchangeable $-\mathrm{NH}$ protons showing peaks at $\delta(\mathrm{ppm})=10.94(\mathrm{~s}, 1 \mathrm{H}), 7.81(\mathrm{~s}, 1 \mathrm{H}), 7.74(\mathrm{~s}$, $1 \mathrm{H}$,$) . Four aromatic doublet protons gives peak at \delta=7.03(\mathrm{~d}, 1 \mathrm{H}, \mathrm{J}=$ $7.5 \mathrm{~Hz}, \mathrm{Ar}-\mathrm{H}), 6.92(\mathrm{~d}, 1 \mathrm{H}, \mathrm{J}=6.9 \mathrm{~Hz}, \mathrm{Ar}-\mathrm{H}), 6.82(\mathrm{~d}, 1 \mathrm{H}, \mathrm{J}=5.7 \mathrm{~Hz}, \mathrm{Ar}-$ $\mathrm{H})$, aromatic multiplet protons provide peak at $\delta=7.315-7.575(\mathrm{~m}$, $2 \mathrm{H}, \mathrm{Ar}-\mathrm{H})$, methane proton appeared at $5.06(\mathrm{~m}, 1 \mathrm{H}, \mathrm{Ali}-\mathrm{CH})$ sulphonamide methylene protons showing peak at 4.33(broad $\left.\mathrm{s}, 2 \mathrm{H},-\mathrm{CH}_{2}\right)$, and two methyl proton indicate peak at $2.75(\mathrm{~s}, 3 \mathrm{H}$, $\left.-\mathrm{CH}_{3}\right), 1.50\left(\mathrm{~d}, 3 \mathrm{H}, \mathrm{J}=6.9 \mathrm{~Hz},-\mathrm{CH}_{3}\right) \mathrm{ppm}$. Also ${ }^{13} \mathrm{C}$ NMR spectra were provide peaks at $\delta=169.0 \mathrm{ppm}$ which shows impurity peak of iodoacetic acid carbonyl carbon, aromatic carbons are absorbed the range of $\delta=155.1,147.7,130.7,129.7,129.5,129.2$, $126.1,123.8,122.8,120.3,113.6,106.3,72.0$. Methine carbon, sulphonamide methylene and methyl, aliphatic methyl group carbon gives peaks at 59.0, 51.7, 42.5, 23.9 respectively. These values confirmed to the number of carbon atoms present in the compound 3.

\section{Conclusion}

In the present work 7-(methanesulphonaminomethyl)-N(1-(3-(trifluoromethyl)phenyl)ethyl)-1H-benzo[d]imidazol-2amine (3) were synthesized successfully from the condensation between compound 1 and 2 in the presence of iodoacetic acid. Most of the researcher have been synthesized 2-aminobenzimidazole derivatives by using hazardous catalyst like mercury(II)oxide, mercury(II)chloride, copper(I) chloride, methyl iodide etc., which involves long time reaction and significant challenges during purification of the products. we have been synthesized 
the 2-aminobenzimidazole derivatives considerably simplified method used by iodoacetic acid as a cyclode sulfirization agent and using ethanol as solvent to provide desired product at $60^{\circ} \mathrm{C}$, 3 hours without formation of side product with high yield.

In our scheme synthesis of compound 1 was involved 6 steps. The first step was protection of diamine followed by bromination and Di BOC amination, BOC deprotection, sulfonation using methane sulfonyl chloride and deprotection of diamine using raney nickel to get key intermediate 1 and 2 was synthesized using amine and thiophosgene. The chemical structures of compound 3 have been confirmed using various spectral techniques viz., FTIR, Mass, ${ }^{1} \mathrm{H}-\mathrm{NMR}$ and ${ }^{13} \mathrm{C}$ spectra and were found to be in agreement with the chemical structures expected.

In literature survey variety of 2 -aminobenzimidazole derivatives were reported using 3,4-substituted diamines and para trifluoro substituted isothiocynates as a key starting material. These derivatives show wide range of biological activity. So in our work we are synthesized various novel 2,3 substituted diamine derivative like compound (1) and various meta trifluoro substituted isothiocynates like compound (2). By using those key intermediates we are synthesized various substituted 2 -aminobenzimidazole like N-((2-(1-(3-(trifluoromethyl) phenyl) ethylamino)-1Hbenzo[d]imidazol-4-yl)methyl)methanesulfonamide(3) which can possibly be further modified to research better potency than the reference drugs.

\section{References}

1. Beaulieu C, Wang Z, Denis D, Greig G, Lamontagne S, O’Neill G, et al. Benzimidazoles as new potent and selective DP antagonists for the treatment of allergic rhinitis. Bioorg Med Chem Lett. 2004;14(12):3195-9.

a. Kling A, Backfisch G, Delzer J, Geneste H, Graef C, Hornberger W, et al. Design and synthesis of 1,5- and 2,5-substituted tetrahydrobenzazepinones as novel potent and selective integrin alphaVbeta3 antagonists. Bioorg Med Chem. 2003;11(7):1319-41. b. Snow RJ, Cardozo MG, Morwick TM, Busacca CA, Dong Y, Eckner RJ, et al. Discovery of 2-phenylamino-imidazo[4,5-h]isoquinolin9-ones: a new class of inhibitors of lck kinase. J Med Chem. 2002;45(16):3394-405.

c. Janssens F, Torremans J, Janssen M, Stokbroekx RA, Luyckx M, Janssen PA. New antihistaminic N-heterocyclic 4-piperidinamines. 1. Synthesis and antihistaminic activity of N-(4-piperidinyl)-1Hbenzimidazol-2-amines. J Med Chem. 1985;28(12):1925-33.

2. Perkins JJ, Zartman AE, Meissner RS. Synthesis of 2-(alkylamino) benzimidazoles. Tetrahedron Lett. 1999;40:1103-1106.

3. Omar AM, Ragab MS, Farghaly AM, Barghash AM. The cyclodesulphurization of thio-compounds. Part 12: A new simple method for the synthesis of $\mathrm{N}$-alpha-substituted benzimidazoles from thiourea derivatives. Pharmazie. 1976;31(6):348-50.

4. Wang X, Zhang L, Zu Y, Krishnamurthy D, Senanayake CH. A practical synthesis of 2-(N-substituted)-amiobenzimidazoles utilizing $\mathrm{CuCl}$ promoted intramolecular cyclization of $\mathrm{N}$-(2-aminoaryl)thioureas. Tetahedron Lett. 2004;45:7167-7170.

5. Mohsen A, Omar ME. The Cyclodesulfurization of Thio Compounds; VII. A New Facile Synthesis of N $\alpha$-Substituted Benzimidazoles. Synthesis. 1974;41-42.

6. Heinelt U, Schultheis D, Jager S, Lindenmaier M, Pollex A, Beckmann HSG. A convenient method for the synthesis of 2-amino substituted aza-heterocycles from N, Nâ€ ${ }^{2}$-disubstituted thioureas using $\mathrm{TsCl} /$ $\mathrm{NaOH}$. Tetrahedron Lett. 2004;60:9883-9888.

7. Omar AMME, Habib NS, Abolwafa OM. The Cyclodesulfurization of Thio Compounds; XVI. Dicyclohexylcarbodiimide as an Efficient Cyclodesulfurizing Agent in the Synthesis of Heterocyclic Compounds from Various Thio Compounds. synthesis. 1977:864-865.

8. Ghosh H, Yell R, Nath J, Patel BK. Desulfurization Mediated by Hypervalent Iodine(III): A Novel Strategy for the Construction of Heterocycles. Eur. J.Org. Chem. 2008;36:6189.

9. Victor Cee J, Nicholas SD. Tetrahedron Lett. 2006;47(22):3747-3750. 